\title{
Research Article: Comparative study on adoption of eco-friendly management practices by vegetable growers
}

\section{Neerja Patel}

Article Chronicle : Received : 26.07.2017;

Revised :

11.12.2017;

Accepted :

27.12.2017

KEY Words : Agrochemical, Ecofriendly farming, Ecofriendly management practice, Farming communities 2012-13.
SUMMARY : The development of India depends on agriculture and it engages about 70 per cent of its population directly or indirectly. It contributes nearly 37 per cent of the net national product and account for a sizable share of total value of the country's export. The area under vegetable crops in Indore district of Madhya Pradesh was about 33.77 thousand hectares in 2011-12, which increased to 6.23 thousand hectares in 2012-13. The production of vegetable crops in Indore district was about 5993.07 thousand tonne in 2011-12 and further increased to 6290.60 thousand tonne in 2012-13 (SourceState Department of Horticulture, Indore M.P.). The present rate of agriculture production could be doubled if the available technology is appropriately transferred to the farmers for its adoption. It is, however, reported that not more than 30 to 40 per cent of the technologies have gone to the farming communities so far, even though there is strong network of extension mechanism operating for accelerating agriculture production. The investigation was undertaken during the year 2008-09 and 2012-13 in purposively selected Indore block of Indore district of Madhya Pradesh. The profile of the vegetable growers was measured on a number of characteristics such as their age, education, annual income, occupation, social participation, socio-economic status, mass media exposure, extension participation and information seeking behaviour. The dependent variables studied were extent of adoption of eco-friendly management practices. Regarding the higher percentage of the respondents $(61.25 \%)$ had medium adoption of eco-friendly management practices in 2008-09 whereas higher percentage of the respondents $(56.25 \%)$ had low adoption of eco-friendly management practices in

How to cite this article : Patel, Neerja (2018). Comparative study on adoption of eco-friendly management practices by vegetable growers. Agric. Update, 13(1): 32-36; DOI : 10.15740/HAS/AU/13.1/32-36. 